Learning from mistakes and moving forward in intercultural research with Aboriginal and Torres Strait Islander peoples

Vanette McLennan $^{1^{\star}}$ and Glenn Woods ${ }^{2}$

${ }^{1}$ School of Allied Health Sciences, Griffith University, Southport, QLD 4222; Menzies Health Institute Queensland, Australia.v.mclennan@griffith.edu.au

* Corresponding Author: v.mclennan@griffith.edu.au

${ }^{2}$ School of Human Services and Social Work, Griffith University, Southport, QLD 4222

\begin{abstract}
The ongoing challenges in equitable research involving Indigenous peoples and their communities and ways to overcome these are discussed in this article. Central to this article is the narrative reflection of a non-Indigenous researcher following research on Indigenous spirituality, wellbeing and resilience in the Yaegl community of northern New South Wales, Australia, conducted between 2003 and 2010. Upon reflection several years after the studies, the researcher has identified several inadequacies in the ways in which the research was conceptualised, designed, conducted and supervised. In seeking to critically reflect on and learn from this experience, with the hope of contributing to better understanding and protocols in research with Indigenous peoples, as well as improved models of HDR supervision in this space, the researcher has collaborated with an Indigenous academic to incorporate theory and Indigenous knowledge in highlighting considerations for better research training and practice.
\end{abstract}

Key words

Intercultural research; Indigenous; supervision; reflexivity 
Indigenous and non-Indigenous researchers are faced with numerous challenges in conducting relevant research in Indigenous communities. Designing research questions that are culturally safe, that align with academic methodological standards and that contribute meaningfully to Indigenous participants and their communities, is indeed difficult to ensure. These issues will be discussed further in this paper, firstly with a collaboratively written brief introduction, followed by an individually authored reflection and response approach, in which a non-Indigenous researcher recalls and critically reflects on her experiences in conducting research in an Australian Indigenous community some years ago. With the passage of time, and further development of research practice knowledge, the researcher has become increasingly concerned and disillusioned about the processes and priorities followed during her PhD candidacy. By engaging an Indigenous academic in exploring these experiences, the intention is to make sense and meaning of the experience and shortcomings so as to better understand how research practices, and particularly research training for HDR candidates, may be enhanced. To conclude, the two authors provide a collaborative discussion incorporating existing literature and best practice examples to highlight some ways forward in intercultural research practice.

Present Western research paradigms and methodologies are informed and influenced by colonisation, globalisation, and imperialism (Chilisa, 2011; Russell-Mundine, 2012) and are limited in flexibility and understanding of historically oppressed communities and their pedagogy and traditions (Foley, 2003; Hall, 2014). Insensitive and poorly designed research continues to appear in academia, furthering mistrust and exploitation (Gray, Hilder, Macdonald, Tester, Dowell, Stubbe, 2017) and the subordination and disempowerment of Indigenous peoples as well as limiting the validity and reliability of findings (Kendall, Sunderland, Barnett, Nalder, \& Matthews, 2011). As a result, Indigenous communities are often deeply sceptical of researchers and feel they receive no concrete benefits to their community (Kendall et al., 2011; Tuhiwai Smith, 1999).

For non-Indigenous researchers conducting research within or centred on Indigenous communities, establishment as an 'outsider' within the Indigenous community creates barriers in the capacity to develop empathetic understanding for the Indigenous experience as a whole and the experiences of the particular community in which the research is conducted (Minniecon, Franks, \& Heffernan, 2007; Foley, 2003). The insider-outsider theory recognises that non-Indigenous researchers cannot possibly understand the complexities of Indigenous Australia on the same level as Indigenous researchers, which can lead to tension and dilemmas that often create culturally confronting or disrespectful research outcomes and guilt for the non-Indigenous researcher (Minniecon et al, 2007; Selby, 2004). The challenges 
in this research space can seem insurmountable and intimidating to non-Indigenous researchers. This is especially so when, as is often the case, they have not been exposed or introduced to Indigenist or decolonising research methodologies, to be discussed in more detail later. It is likely that many experienced and early-career researchers have been deterred from developing research pertaining to or involving Indigenous peoples for fear of doing or saying 'the wrong thing'. It may feel more natural and safe for non-Indigenous researchers to rely on the scientific Western method, which is the basis of their training and engrained in academic culture, than to take on the challenges and 'unknowns' of intercultural research and non-Western methods of inquiry. This feeling is echoed by other nonIndigenous researchers who have expressed concerns and unease associated with crosscultural research (Aveling, 2012; Hall, 2014; Minniecon et al, 2007). The risk is that nonIndigenous researchers may be deterred from commencing or continuing research within this space, despite good intentions and the potential to conduct transformational research if provided opportunities to learn new ways of approaching, hearing and documenting Indigenous voices and traditions in culturally safe ways (Martin, 2003, 2014). The reflection and response that follows provides a closer look at some of these risks involved when researchers are under-prepared for meaningful intercultural learning.

Non-Indigenous researcher reflection:

The reasons behind my personal interest in Indigenous health issues and decision to undertake $\mathrm{PhD}$ research in the local Indigenous community of my hometown were wideranging, if a little naïve. As a non-Indigenous woman, I have long admired the spiritual and cultural realms of Indigenous Australians, and the interconnectedness of land, family and community in Indigenous culture and wellbeing. Growing up in the Clarence Valley on the far north coast of New South Wales, I was surrounded by Indigenous people, although theirs was certainly the minority culture in a deeply Anglo-Australian and largely conservative broader community. Some of the local Yaegl people were indeed weakened by the forces of social oppression and disadvantage, while many others were providing strong leadership in their community. I witnessed the racism targeted at the Indigenous community and the disparities in schooling, housing, health and employment, and felt a need to know more about their traditional culture and of the consequences to Indigenous Australia since European invasion. In other words, I was beginning to engage in a classic case of 'othering', you might say.

Indigenous academic response:

In reading Vanette's brief introductory reflection here I get an immediate sense of the power and impact of some of the most dominant paradigms at play in Australia in regards to ideas 
about and relationships with Indigenous peoples, in social and academic spaces. Despite at least 200 plus years of interaction in south east Australia between Indigenous and nonIndigenous peoples there remains a clear sense that Indigenous peoples, cultures and communities are separate and different from the mainstream 'norm'; so much so that they remain something of a 'mystery' or unknown quantity to a majority of non-Indigenous people, even when people live amongst each other in particular towns and regions for generations. Indigenous people are the 'other' as a result of a continuing process of 'othering' that began well before any Anglo/Celtic immigrant and settler ever set foot in Australia (Jones, 1989).

We can get a sense of the roots of this othering and how it worked by examining both popular fiction and non-fiction of Europeans in the eighteen and nineteen hundreds. Indigenous people were stereotypically defined and described as primitive, brutal, barbaric and dangerous both physically and morally (Egglison, 2001; Lake \& Reynolds, 2008). With the emergence of race theory and eugenics in the late 19th century, the othering of Indigenous peoples in Australia became more formalised via government legislation and policy (Reynolds, 1996). It was broadly academically supported and scientifically justified and arguably remains a powerful dynamic within Australian social, political and academic spaces today.

In a more contemporary critical academic context Edward Said is recognised as bringing the discussion about colonialism and othering to the fore. Presented in the context of Orientalism and the West, Said presents a number of concepts that are directly relevant to the context in which Vanette is referring to in this reflection, including:

"Orientalism was ultimately a political vision of reality whose structure promoted the difference between the familiar (Europe, West, "us") and the strange (the Orient, the East, "them"." (Said, 1978, p43).

Vanette confirms that she grew up surrounded by Yaegl people in the Clarence region of NSW. She has reflected on her observations of discrimination and oppression directed at Yaegl people, perhaps due to her cultural co-membership with the hegemonic Anglo Australian culture. Vanette also reflects on her sense of the impacts this discrimination and oppression had on the Yaegl people, that it "weakened" people and communities. However despite living side by side with Yaegl people in the geophysical sense it seems clear that much of the Yaegl philosophies, values, ways of being and day-to-day lives were still unknown to her. Even in this opening section Vanette's reflection indicates her sense of the Yaegl community and culture, as she imagined it, via information and lessons that did not 
necessarily come from direct social and educational interaction with Yaegl people. Vanette states that she had "long admired the spiritual and cultural realms of Indigenous Australians and the interconnectedness of land, family and community in Indigenous culture and wellbeing". However she qualifies this as "a classic case of othering" rather than a socially experienced knowledge.

Reflection continued:

I undertook studies in Indigenous health while completing an undergraduate health science degree. Unfortunately, learning in the area of Indigenous health was predominantly focused on community deficits and the determinants of ill-health and disadvantage. Out of an interest in the positives that I had witnessed in the Yaegl community, I became more involved with the community. This involvement was in the shape of an honours study and thesis, not out of benevolence or a quest for social justice, so perhaps just the first of many selfish academic moves, if I'm honest. That said, it wasn't a study focused on particularly sensitive content, it was a study that highlighted the interconnectedness of spirituality and culture with wellbeing in the Yaegl community (McLennan, 2003; McLennan \& Khavarpour, 2004). What did the Yaegl community get out of this involvement? Nothing, except the chance to talk about the topic with someone, and even then it was with someone investigating through a white lens.

Response continued:

In this part of her reflection Vanette is describing what I believe to be a very common and ongoing nexus between tertiary education and research about Indigenous peoples as the ongoing 'other'. The common thread between Vanette's undergraduate education experience and her transition into research is the lack of Indigenous control regarding Indigenous subjectivity; in terms of content, context and process.

Vanette reflects on her undergraduate education as being focussed on Indigenous community deficits and on deficit topics such as ill health and disadvantage. This experience is indicative of the power and influence of the deficit paradigm at play. This paradigm is also part and parcel of the othering process discussed by Said whereby the non-Western other is inherently inferior in comparison to the superior Western benchmark (Said, 1978). The narrative of the deficit paradigm story typically involves a plot that problematises the unfortunate situation and perhaps the culture of the Indigenous other, then moves on to find solutions within the existing colonising structure via dominant hegemonic practices. Existing colonising structures and dominant hegemonic processes are not identified and scrutinised within this story. They are not part of the compelling narrative. The practitioners of dominant 
hegemonic practice in colonised spaces are the heroes of this narrative, whilst Indigenous communities and peoples are the subjects and scenery.

Linda Tuhiwai Smith defines and critically examines the ongoing colonisation of Indigenous peoples, communities and cultures within and by the academy in her groundbreaking book, Decolonizing Methodologies (Smith, 1999). Dr Smith is one of a number of Indigenous academics who have been developing discussions and actions based on an alternative narrative to the colonising and deficit-based stories. These narratives are based on Indigenous and Indigenist research theories, methodologies and practices. The body of work based on Indigenist theory and practice, Indigenous research methodology and decolonising practice has been building steadily for the best part of two decades within Australia and Internationally. To this end there is a broad, comprehensive and accessible catalogue of academic papers, journals and books available yet this work seems to remain at the margins, at best, within courses and programs developed to support and inform early career researchers.

It is interesting that Vanette reflects on her early research experience as being motivated by selfishness and a self-serving desire to focus on positives within Indigenous communities rather than negatives. She states that her motivation was not based on "benevolence or a quest for social justice". My sense of Vanette's motivation was that there was an underlying desire to challenge the deficit paradigm and to present a strengths-based narrative, however, she had not been exposed to de-colonising, anti-oppressive conceptual frameworks and research methodologies. It seems her self-judgement is somewhat harsh here, particularly given what she had been given to work with as reference points and understandings up until that point. Nevertheless, her reflections on the research space being self-serving and lacking in a social justice agenda are perceptive and have been discussed in detail by Indigenous and non-Indigenous academics whose work is focused on antioppressive, de-colonising and Indigenous rights based concepts and methodologies (See Smith, 1999; Rigney, 2006; Denzin \& Lincoln, 2008).

Reflection continued:

Luckily, my relationships in the community remained strong despite my seemingly selfish 'take-and-no-give' approach. My understanding of and interest in the inextricable links between family, community, culture and spirituality in Indigenous identity and wellbeing strengthened, albeit again through my own myopic view and understanding of the world. Nonetheless, I felt inspired and passionate "about the strengths and what appeared to be sheer resilience of Indigenous Australians and their communities, and perplexed that these 
were too often ignored or denied in media and government reports" [excerpt from PhD Introduction (McLennan, 2009)]. So, what did a naïve white girl think she could do about it? Well, at the time I honestly believed that 'doing' yet another study would cut it, and a PhD candidature was born. The main motivation for the study was not academic advancement, I was quite happy in my day job as a rehabilitation counsellor. I had high hopes that "an improved understanding and respect for the existing strengths and resources in Indigenous communities could enhance the approach of practitioners and communities alike in attempts to strengthen health and social outcomes" [PhD excerpt]. Just another form of hyperbole common among PhD candidates, many experienced academics may remark. But, did I look to change the research approach based on the flaws of my first study? No. Did my academic supervisors suggest a more appropriate Indigenous methodology, perhaps with Indigenous research partners instead of them merely being respondents? No. Did I allow reflexivity in the development of the research questions based on community need and determination? No. Did the university's human research ethics committee or the Aboriginal Health and Medical Research Council make requests beyond perfunctory tick-box actions espoused by the relevant 'guidelines' of the time? No. The list of neglected actions could go on. Hence, my now long-held dissatisfaction with those four years of my life, the thesis hidden at the back of my shelf collecting dust, and my disillusionment with the whole idea of nonIndigenous research of Indigenous anything.

Needless to say, I haven't the confidence or nerve to consider further research in a field I once felt passionately about. I can't shake the sense that I abused my privileged position of trust and social connection within the community, and I deeply regret that I missed an opportunity to make a genuine contribution in the community that I sincerely respect. From research conception to dissemination stage, there were better practices and approaches that could have been taken to ensure it was more community driven, ethical and meaningful. As it stands, less than 2 pages of the PhD dissertation (out of a total 242) are dedicated to ethical and cultural considerations in the methodological development of the study. I now can't believe this wasn't further questioned by my supervisors and examiners. Further, the research design, data collection, analysis and interpretation, were from a privileged AngloAustralian young woman's perspective, and while I declared my attempts to phenomenologically bracket my own experiences and ways of viewing the world, let's be realistic. Our own cultural and familial backgrounds will ultimately, and often unconsciously, influence the ways in which we interpret, emphasise and utilise the information and experiences obtained in research. There is no way of truly losing the 'self' in research, at least not in qualitative research. So, how can we best declare our perspectives in a 
meaningful way, and ensure the analysis of data stays true to the perceptions and experiences generously divulged by those who offer them?

A comment I made in writing my* $\mathrm{PhD}$ thesis, while pointing to some of the issues of my being a non-Indigenous researcher, was around the privileged position I held based on the trust and rapport previously developed with some community members. I suggested that non-Indigenous researchers would benefit from developing "meaningful and respectful partnerships with Indigenous people from the community in which their research is planned" (McLennan, 2009). My belief was, and remains, that these partnerships are crucial to the value of research. While this may be true, how can we do this without it being tokenistic, disingenuous, or worse, deceptive? I understand now that these partnerships must be far more than based on respect between researcher and participant, but researcher and coresearcher, where the goal is equal mutual benefit. Setting up these partnerships may be time consuming and costly, but without them, a study is destined to end up in the alarmingly large pool of dissertations with little or no impact, or worse, untoward outcomes.

* The researcher acknowledges issues of ownership inherent in the use of 'my' here due to the contested nature of ownership of intellectual property of Indigenous research.

Response continued:

In considering Vanette's further reflection here I can see three clear issues that stand out as critical lessons for those considering undertaking research that involves Indigenous community engagement or that considers Indigenous philosophies, beliefs, values or processes.

The first issue is the degree to which researchers, research supervisors and research partners, such as Indigenous communities or organisations are informed and prepared to engage the research process. Vanette's story makes it clear that her entire educational experience right up until this point had not prepared her to approach and conduct her research project with an Indigenous community in the most equitable, meaningful and valuable way possible. It seems she made the best of what she had to draw on and it appears to me that her intention had integrity. Whilst Vanette reflects that she felt her approach was "take and no give", the idea of reciprocity and mutual benefit between researcher and 'researched' is unlikely to be considered a key component in a typical Western research methodology, which is now widely problematised among social science researchers. On the other hand, the process of reciprocity and mutual benefit is likely to be a 
key component of an Indigenous research methodology (See Kovach, 2015; Chilisa, 2011; Wilson, 2003).

Good intentions and a classic Western research approach are likely to be ineffective at best and damaging at worst. In this case the huge research effort that goes into producing a $\mathrm{PhD}$ study has been ineffectual, producing a document that has been effectively shelved, hidden and inactive as a tool for social justice and improved professional practice. An opportunity to produce meaningful quality knowledge has been lost. It's also clear that this outcome weighs very heavily on Vanette and has led to feelings of regret and remorse associated with her postgraduate research. It is unclear what the Indigenous community participants may think or feel without re-engaging them in a follow-up process. Suffice to say their experience is not uncommon, unusual or a thing of the past (Rigney, 2006).

In considering Vanette's lack of preparedness we should also consider the Indigenous participants' lack of preparedness. This goes far beyond 'informed consent'. If community members and representative organisations are not informed and educated about the types of research methods and practices available they too may go blindly into the process with good intentions and high hopes only to be left wondering what the point of it all was, or worse, feeling disgruntled and let-down. A great deal of trust continues to be put in institutions and individual researchers despite the history of research being a story of colonisation and appropriation far more than a story of liberation and empowerment (Moreton-Robinson, 2004).

In my opinion it is the academic institution and the senior research staff that are to be held most accountable in this situation. Undergraduate and postgraduate students are at once informed and limited by the depth and breadth of knowledge, understanding and vision held by academic staff both in course content and research approach and application.

There has been broad and accessible academic discussion available for the best part of two decades in regards to the limits and dangers of research that is focussed on or about Indigenous people and generated by the academy. As previously mentioned Linda Tuhiwai Smith's work represents an international perspective, as does the work of Marie Battiste (Battiste, 2011), however, there has been extensive discussion generated by Indigenous Australian academics and their colleagues, across a range of disciplines (See for example Nakata, 2007; Rigney, 2006; Moreton-Robinson, 2006). 
Given the prevalence and accessibility of these important discussions and the availability of Indigenous research methodologies why are we still finding ourselves in situations such as that being reflected on here by Vanette? Despite the availability of critical discussion, clear guidelines and appropriate research approaches there still appears to be reluctance within the academy, and perhaps more so in the health sciences than in other disciplines (Bainbridge et al., 2015; Kendall et al., 2011; Saunders, West, \& Usher, 2010), to engage with Indigenous communities and organisations on truly equitable terms and to frame and design research around what Indigenous peoples are identifying as critical and relevant issues. This makes sense given the long and well-established colonising paradigm that Western institutions have developed in regards to the researching of Indigenous peoples (Smith, 1999) as opposed to the researching with Indigenous peoples in a process that is mutually beneficial and liberating (Rigney, 2006).

It is also worth considering that whilst there is now a broader range of valuable course-work type studies available to undergraduate students in areas that identify and highlight relevant issues such as white privilege, cultural safety, cultural humility and de-colonising practices, it may be that senior academics were never introduced to these concepts and practices within their own training and ongoing professional development. Whilst it is likely that postgraduate supervisors and research centre staff enter into projects that involve Indigenous participants with good intentions, it could be that they too need to develop their understandings and knowledge before they can become effective leaders, supervisors and mentors.

I imagine that it takes a good deal of humility for people considered experts in academic research to come to terms with the idea that the processes and practices they have been directly or in-directly involved in as researchers and academic administrators may not have been beneficial to Indigenous peoples and communities, despite good intentions. Indeed these practices may have maintained a debilitating and imperialistic paradigm that has led to the numerous dust-gathering, ineffective and benign studies and documents Vanette has alluded to. It may help explain why there is a tendency for early career researchers to be enthusiastic about research that involves Indigenous people only to shy away from continuing their research in this space.

Vanette has been willing to listen to her intuitive sense of dissatisfaction and regret with a process she played an active and key role in. She has found the courage to identify and move beyond her privileged position both socially and professionally and to recognise the short-comings of a research paradigm that does not give agency to the Indigenous voice nor include Indigenous concepts and practices of knowledge generation. I invite all colleagues 
involved in academic research to reflect deeply on Vanette's story and to consider the lessons and opportunities offered. Let's not continue to engage ineffective and inequitable research practices that do little to support equity and social justice for Indigenous peoples.

\section{Reflection conclusion:}

The process of evaluating and reflecting on my previous practices and the sense of shame stemming from my postgraduate research experience has contributed to a deep learning and heightened consciousness of the need to engage with decolonising and Indigenist research methodologies. I thank Glenn for the sensitive and considered approach he has taken in helping to make meaning of my experiences, and the suggestions called upon to enrich research practice while safeguarding Indigenous knowledges and cultures. I have learned that my experience is not unique and that with improved preparation and supervision, through engagement with examples of better-practice, my research impact and trajectory could have been quite different. While I still feel a sense of inadequacy in relation to involvement in future Indigenous-centred research, I'm committed to continuing my 'unlearning' of colonising research practices as well as learning from those who have successfully forged ahead with meaningful and equitable intercultural research. I strongly encourage all researchers, particularly those considering research in intercultural contexts, to critically engage with the methodological literature, to challenge the traditional Western models of research practice within intercultural contexts, and to adopt cultural humility and reflexivity in their practice. Without looking back and learning from past mistakes, and being open to new models of research design, transformational steps forward in intercultural research are unlikely.

\section{Collaborative Conclusion: Ways Forward}

In order to create research that moves away from the colonial standards that often oppress Indigenous groups, research practice and the training of new researchers must prioritise a commitment to understanding and enacting post-colonial Indigenous research paradigms. These paradigms espouse decolonising methodologies, whereby non-Western ways of knowing and being are included and legitimised as meaningful forms of knowledge. In order to create a more decolonised and culturally safe research environment, Indigenous Standpoint Theory is promoted as a 'marriage' of approaches from both Indigenist research paradigms and typical Western research requirements (Foley, 2003; Kendall et al, 2011). Indigenous Standpoint Theory promotes the use of Indigenous epistemologies and voices within research (Aveling, 2012; Hall, 2014; Minniecon et al, 2007), and demands that nonIndigenous researchers approach research with flexibility and respect for the need to 
develop trustworthy and transparent relationships (Aveling, 2012; Jalla \& Hayden, 2014; Minniecon et al, 2007). Further, Indigenist research paradigms call for the inclusion of Indigenous researchers and key community stakeholders; a reflexive practice for nonIndigenous researchers; and the inclusion of Indigenous values, customs, and epistemologies, with the aim of empowering Indigenous communities through culturally safe research (Coram, 2011; Hall, 2014; Kendall et al, 2011; Minniecon et al, 2007).

Using values that are "commensurate with Indigenous knowledge traditions" (Hall, 2014, p.385) - for instance, the role of land in social structures, cosmology and spirituality (MeoSewabu, 2014) - will allow researchers, both Indigenous and non-Indigenous, to maintain a two-way transaction of communication that empowers the Indigenous community to express personal experiences (Jamieson et al., 2012; Suaalii-Sauni \& Fulu-Aiolupotea, 2014). Inclusion of the community, orientation toward the community, and the flexibility to deliver tangible outcomes are all-important facets of Indigenist research, that when employed correctly, increase participation and decrease oppression (Furness, Nikora, Hodgetts \& Robertson, 2015; Henry et al., 2002; Jalla \& Hayden, 2014; Jamieson et al., 2012). However, the crucial underpinning of all Indigenist research is the understanding that there is diversity amongst the Indigenous population (Jalla \& Hayden, 2014; Jamieson et al., 2012). Each community has different experiences, customs, and protocols, which makes the inclusion of an Indigenous researcher or a community partner an integral aspect for successful, culturally appropriate research outcomes.

Employing or engaging an Indigenous researcher can help non-Indigenous researchers build respectful community collaboration that will transcend the insider-outsider relationship, which traditionally characterises non-Indigenous research in an Indigenous community (Isaacs et al, 2011; Jalla \& Hayden, 2014; Kendall et al, 2011; Marshall et al, 2008; Martin, 2014). An Indigenous researcher from within the community can help promote transparent and honest communication, which in turn leads to a sense of community control and ownership over the research and its outcomes (Marshall et al, 2008; National Health and Medical Research Council, 2003). Community involvement and consultation also enables reciprocal learning and cross-cultural hybridization, which bridges the fundamental gaps between researcher and participants, Indigenous and non-Indigenous (Kelly et al, 2012; Marshall et al, 2008; Selby, 2004). Community involvement must extend beyond the traditional researcher and subject relationship, and become an integral part of the research pedagogy, particularly in terms of HDR supervision (Pyett, Waples-Crowe \& van der Sterren, 2008). Students, particularly $\mathrm{PhD}$ candidates should receive mentorship from Indigenous academics (Elston, 
Saunders, Hayes, Bainbridge \& McCoy, 2013) and informed supervisors in order to fully understand, embrace, and employ Indigenist approaches in their research (Saunders, West, \& Usher, 2010). Whenever possible, researchers should also look for opportunities to develop a framework for collaborative writing-up of the findings, so as to ensure that benefits are flowing back toward the community (Isaacs et al, 2011; Jamieson, 2012). These actions will require researchers to look beyond the traditional research ethics guidelines, to challenge universalist assumptions and to prioritise trust and reciprocity in intercultural research (Gray et al., 2017).

Improved approaches to intercultural research will require the repositioning of humanity and respect to the forefront of research, something that has been lacking in the majority of research in this field. Humility, and perhaps more specifically cultural humility (Tervalon \& Murray-Garcia, 1998; Hook, Davis, Owen, Worthington \& Utsey, 2013), will be essential in creating a more equitable and socially just relationship between researchers and those that become the participants and informants within the research process. In the words of two young PhD candidates, cultural humility requires us to "be humble and flexible, bold enough to look at ourselves critically and desire to learn more" (Waters and Asbil, 2013, para. 3). The reflection presented in this article is an example of the cultural humility and reflexivity process. This approach, in combination with an appropriate and critical literature review, can be highly effective as the precursor to any research project involving Indigenous peoples, knowledges and cultures, particularly knowledges and cultures that have been subjugated. Cultural humility can indeed become a method used throughout the entire research process, regardless of the focus, as it requires the researcher to engage in an ongoing dialogue and learning with research participants.

Thanks to the work of Indigenous academics, activists and their allies there is now a large and growing body of work available to draw on and learn from. If this work and the guidance contained within it is engaged with and respected, researchers from any discipline should be able to approach research in Indigenous spaces with a sense of optimism and confidence. 
References

Aveling, N. (2012). 'Don't talk about what you don't know' : on (not) conducting research with/in Indigenous contexts. Critical Studies in Education, 54(2), 203-214.

Bainbridge, R., Tsey, K., McCalman, J., Kinchin, I., Sauders, V., Watkin Lui, F., CadetJames, Y., Miller, A., \& Lawson, K. (2015). No one's discussing the elephant in the room: contemplating questions of research impact in ATSI Australian health research. BMC Public Health, 15, 696-797. doi: 10.1186/s12889-015-2052-3

Battiste, M. (2011). Reclaiming Indigenous voice and vision. UBC Press.

Chilisa, B. (2011). Indigenous research methodologies. Sage Publications.

Coram, S. (2011). Rethinking Indigenous Research Approval. Qualitative Research Journal, 11(2), 38-47.

Denzin, N. K., \& Lincoln, Y. S. (2008). Handbook of critical and indigenous methodologies. Sage.

Egglison, T. (2001). Myth of the noble savage. UC Press.

Elston, J. K., Saunders, V., Hayes, B., Bainbridge, R., \& McCoy, B. (2013). Building indigenous Australian research capacity. Contemporary Nurse: A Journal for the Australian Nursing Profession, 46(1), 6-12. doi: 10.5172/conu.2013.46.1.6

Foley, D. (2003). Indigenous epistemology and Indigenous standpoint theory. Social Alternatives, 22(1), 44-52.

Furness, J., Nikora, L., Hodgetts, D., \& Robertson, N. (2015). Beyond Ethics to Morality: Choices and Relationships in Bicultural Research Settings. Journal of Community and Applied Social Psychology.

Gray, B., Hilder, J., Macdonald, L., Tester, R., Dowell, A., \& Stubbe, M. (2017). Are research ethics guidelines culturally competent? Research Ethics, 13(1), 23-41. doi: $10.1177 / 1747016116650235$

Hall, L. (2014). 'With' not 'about' - emerging paradigms for research in a cross-cultural space. International Journal of Research \& Method in Education, 37(4), 376-389.

Henry, J., Dunbar, T., Arnott, A., Scrimgeour, M., Matthews, S., Murakami-Gold, L., \& Chamberlain, A. (2002). Indigenous Research Reform Agenda. Rethinking research methodologies. Cooperative Research Centre for Aboriginal \& Tropical Health, Links Monograph Series: 2, 1-15.

Hook, J. N., Davis, D. E., Owen, J., Worthington Jr., E. L., \& Utsey, S. O. (2013). Cultural humility: Measuring openness to culturally diverse clients. Journal of Counseling Psychology, 60(3), 353-366. doi:10.1037/a0032595

Isaacs, A. N., Pepper, H., Pyett, P., Gruis, H. A., Waples-Crowe, P., \& Oakley-Browne, M. A. (2011). 'What you do is important but how you do it is more important'. Qualitative Research Journal, 11(1), 51-61. 
Jalla, C., \& Hayden, G. (2014). Aboriginal health research is not black and white- lessons from the field. Australian Indigenous Health Bulletin, 14(3), 1-4.

Jamieson, L., Paradies, Y., Eades, S., Chong, A., Maple-Brown, L., Morris, P., Bailie, R., Cass, A., Roberts-Thomson, K., Brown, A. (2012). Ten principles relevant to health research among Indigenous Australian populations. The Medical Journal of Australia, 197(1), 16-18.

Jones, R.S. (1989) "Book Review Essay: Black Literature and Society in the Eighteenth Century," Trotter Review: Vol. 3: Iss. 3, Article 6.

Kelly, J., Saggers, S., Taylor, K., Pearce, G., Massey, P., Bull, J., Ahboo, S. (2012). "Makes you proud to be black eh?": Reflections on meaningful Indigenous research participation. International Journal for Equity in Health, 11(40), 1-8.

Kendall, E., Sunderland, N., Barnett, L., Nalder, G., \& Matthews, C. (2011). Beyond the rhetoric of participatory research in Indigenous communities: Advances in Australia over the last decade. Qualitative Health Research, 21(2), 1719-1728.

Kovach, M. (2015). Emerging from the margins: Indigenous methodologies. Research as Resistance, 2e: Revisiting Critical, Indigenous, and Anti-Oppressive Approaches, 43.

Lake, M., \& Reynolds, H. (2008). Drawing the global colour line: white men's countries and the international challenge of racial equality. Cambridge, 18, 5.

Marshall, C. A., Kendall, E., Catalano, T., \& Barnett, L. (2008). The spaces between:

Partnerships between women researchers and Indigenous Women with disabilities.

Disability and Rehabilitation, 30(3), 191-201.

Martin, K. (2003). Ways of Knowing, Being and Doing: A Theoretical Framework and Methods for Indigenous and Indigenist Re-search. Journal of Australian Studies, 76(1), 203-214.

Martin, K. (2014). Aboriginal Research, Ethics and Methodology: What's the Difference? , Griffith University, 9 September 2014.

McLennan, V. (2003). Australian Indigenous Wellbeing: Yaegl Community Points of View. Aboriginal and Islander Health Worker Journal, 27(5), 8-9.

McLennan, V. (2009). The role of family and community resilience in Indigenous wellbeing. Unpublished PhD thesis., The University of Sydney, Sydney.

McLennan, V., \& Khavarpour, F. (2004). Culturally Appropriate Health Promotion: Its Meaning and Application in Aboriginal Communities. Health Promotion Journal of Australia, 15(3), 237-239.

Meo-Sewabu, L. (2014). Cultural discernment as an ethics framework: An Indigenous Fijian approach. Asia Pacific Viewpoint, 55(3), 345-354. 
Minniecon, D., Franks, N., \& Heffernan, M. (2007). Indigenous Research: Three researchers reflect on their experiences at the interface. The Australian Journal of Indigenous Education, 36(Supplement), 23-31.

Moreton-Robinson, A. (2004). Whiteness, epistemology and Indigenous representation. Whitening race: Essays in social and cultural criticism, (1), 75-88.

Moreton-Robinson, A. (2006). Towards a new research agenda? Foucault, Whiteness and Indigenous sovereignty. Journal of Sociology, 42(4), 383-395.

National Health and Medical Research Council. (2003). Values and Ethics: Guidelines for Ethical Conduct in Aboriginal and Torres Strait Islander Health Research. Canberra: Commonwealth of Australia.

Pyett, P., Waples-Crowe, P., \& van der Sterren, A. (2008). Challenging our own practices in Indigenous health promotion and research. Health Promotion Journal of Australia, 19(3), 179-183.

Tervalon, M., \& Murray-Garcia, J. (1998). Cultural humility versus cultural competence: A critical distinction in defining physician training outcomes in multicultural education. Journal of Health Care for the Poor and Underserved, 9(2), 117-125. doi: 10.1353/hpu.2010.0233

Nakata, M. N. (2007). Disciplining the savages, savaging the disciplines. Aboriginal Studies Press.

Reynolds, H. (1996). Aboriginal sovereignty: reflections on race, state, and nation. Allen \& Unwin.

Rigney, L. I. (2006). Indigenist research and aboriginal Australia. Ashgate.

Russell-Mundine, G. (2012). Reflexivity in Indigenous research: Reframing and decolonising research? Journal of Hospitality and Tourism Management, 19, 1-6.

Said, E. (1979). Orientalism. 1978. New York: Vintage, 1994.

Saunders, V., West, R., \& Usher, K. (2010). Applying Indigenist research methodologies in health research: Experiences in the Borderlands. The Australian Journal of Indigenous Education, 39(Supplement), 1-7.

Selby, J. (2004). Working divides between Indigenous and non-Indigenous: Disruptions of identity. International Journal of Qualitative Studies in Education, 17(1), 143-156.

Smith, L. T. (1999). Decolonizing Methodologies. Dunedin, NZ: University of Otago Press.

Suaalii-Sauni, T \& Fulu-Aiolupotea, S. (2014). Decolonising Pacific research, building Pacific research communities and developing Pacific research tools: The case of the talanoa and the faafaletui in Samoa. Asia Pacific Viewpoint, 55(3), 331-344.

Waters, A. \& Asbil, L. (2013). Reflections on cultural humility. Retrieved from http://www.apa.org/pi/families/resources/newsletter/2013/08/cultural-humility.aspx 
Wilson, S. (2003). Progressing toward an Indigenous research paradigm in Canada and Australia. Canadian Journal of Native Education, 27(2), 161-178. 